\title{
Emotions Across Cultures
}

Roza G. Kamiloğlu ${ }^{1}$, YongQi Cong ${ }^{1}$, Rui Sun ${ }^{1}$, and Disa A. Sauter ${ }^{1}$

${ }^{1}$ Department of Psychology, University of Amsterdam

Correspondence concerning this article should be addressed to to Roza G. Kamiloğlu, Department of Psychology, University of Amsterdam, REC G, Nieuwe Achtergracht 129B, 1001 NK, Amsterdam, The Netherlands.

Contact: r.g.kamiloglu@uva.nl

Manuscript information: 8162 words

To cite this article (APA):

Kamiloğlu, R. K., Cong Y., Sun, R., \& Sauter, D. A. (in press). Emotions across cultures. In L. Al-Shawaf \& T. K. Shackelford (Eds.), The Oxford handbook of evolution and the emotions. Oxford University Press. 


\begin{abstract}
What can evolutionary theories tell us about emotions, and how can research on emotions inform evolutionary theories? In this chapter, we discuss links between evolutionary theories of emotion and the cross-cultural study of emotion. We examine what predictions can be derived from evolutionary theories about cross-cultural consistency and variability. In particular, we emphasise the notion that evolved psychological mechanisms result in cultural differences instantiated as variations on common themes of human universals. We focus on two components of emotions: emotion experience and nonverbal expressions. Several case studies from emotion science are outlined to illustrate this framework empirically. In the domain of emotion experience, we highlight shame as an illustration of the idea of variations occurring across cultures around a common theme. In the domain of nonverbal expression of emotion, this idea is illustrated by the in-group advantage, that is, superior recognition of emotional expressions produced by members of one's own group. We consider both statistical learning and motivational explanations for this phenomenon in light of evolutionary perspectives. Lastly, we review three different theoretical accounts of how to conceptualise cross-culturally shared themes underlying emotions. We conclude that the cross-cultural study of consistency and variation in different emotion components offers a valuable opportunity for testing predictions derived from evolutionary psychology.
\end{abstract}




\section{Introduction}

What can evolutionary psychology tell us about consistency and variability in human emotion across cultures? A growing body of research provides cross-cultural data on numerous features of emotion, including expressions (e.g., Elfenbein, Beaupre, Levesque \& Hess, 2007; Tracy \& Matsumoto, 2008), perception (e.g., Cordaro et al., 2016; Crivelli, Russell, Jarillo, \& Fernández-Dols, 2017; Laukka et al., 2013), regulation (e.g., Liddell \& Williams, 2019; Pauw et al., 2020), and experience (e.g., Sun et al., 2020). This work underscores the interests in empirical tests of the extent to which components of emotions vary across cultures. Evolutionary psychology can offer a useful framework for such endeavours. Cross-cultural differences are consistent with an evolutionary psychological approach to emotions. Despite common belief to the contrary, evolved mechanisms do not imply strict uniformity (Apicella \& Barrett, 2016; Tooby \& Cosmides, 1992). Evolved mechanisms are expected to produce culturally variable output (e.g., physiological or behavioural changes) in response to variable input in terms of the local environment and culture (e.g., Al-Shawaf \& Lewis, 2017). Interaction of evolved psychological mechanisms with a wide range of human environmental and cultural conditions might thus be expected to produce variability in psychological output between human populations. Here, we argue that evolutionary psychology can offer a lens to view the ways through which evolved systems give rise to universal and culturally variable outcomes in the domain of human emotion.

In this chapter, we examine the intersection between evolutionary theories and the study of emotions across cultures. We examine what predictions can be derived from evolutionary theories about cross-cultural consistency and variability of emotion, and highlight the benefits that can be gleaned from their integration. To do so, we first explicate the notion that evolved psychological mechanisms result in cultural differences instantiated as variations around common themes of human universals. Next, we consider this idea in relation to two different components of emotion: experience and nonverbal expressions. We do not comprehensively review the available empirical evidence, but instead provide case studies as illustrative examples, and point readers to resources for further reading. Finally, we discuss three frameworks of emotion theory in terms of their proposals for what constitutes the evolved, cross-culturally shared themes underlying emotions.

\section{Evolved psychological mechanisms can yield consistency and variability}

An evolutionary psychological approach posits species-typical psychological mechanisms (Lewis et al, 2017). Influential conceptions of evolutionary psychology hold that the human mind is a product of mechanisms that evolved by natural selection to solve particular adaptive problems faced in ancestral environments over long periods of time (Tooby \& Cosmides, 1990, 1992). Adaptive problems refer to conditions that would have had a recurrent impact on an organism's chances of survival and reproductive success, such as avoiding predators, kin detection, attracting a mate, finding nutritious food, and protecting offspring. On this view, the presence of recurrent yet varied adaptive problems would have favoured the evolution of functionally specialized mechanisms (but see L. F. Barrett, 2011). Such mechanisms might include sensory, perceptual, affective, and behavioural features that work together to facilitate rapid and effective responses to solving specific kinds of challenges (Barrett \& Kurzban, 2006; Cosmides \& Tooby, 1994; but see Anderson \& Finlay, 2014; Stephen, 2014; Zerilli, 2017).

Evolutionary psychology has tended to emphasise the universality of human psychology (Tooby \& Cosmides, 1992). The idea of a universal human nature can easily be taken to mean that specific behaviours must be universal: While universality claims based on 
evolutionary theorising imply biological underpinnings, any systematic variation in human psychology and behaviour is assumed to be evidence for cultural differences that are not evolved (see Apicella \& Barrett, 2016). However, evolution does not necessarily yield uniform results across contexts; evolutionary processes have resulted in highly diverse cultural repertoires of human populations. Human cultural capacities are part of evolved psychological mechanisms (e.g., Heyes, 2020; Richerson \& Boyd, 2005). Culture is a human universal, yet culture is obviously a source of variability in human psychology and behaviour (Kline, Shasudheen, \& Broesch, 2018). Variation is thus not equivalent to a lack of universality, nor does universality imply a lack of cultural influence. Debates around universality are often framed as competing explanations set up as dichotomies: innatelearned, nature-nurture, or biological-cultural. However, elaborating on the relationship between evolution and culture first requires recognizing that evolutionarily prepared and culturally learned processes are not incompatible but rather complementary. Only then can we begin to understand how evolved psychological mechanisms can create psychological and behavioural variation as well as consistency across populations (H. C. Barrett, 2014).

Evolutionarily prepared and culturally learned mechanisms are thus not mutually exclusive explanations of consistency and variability. Individuals are endowed with the inclination to be easily conditioned to some type of stimuli, or to learn some things more easily than others; these are considered innate prepared mechanisms (e.g., Al-Shawaf, Lewis, Barbaro, \& Wehbe, 2020; Al-Shawaf, Lewis, Wehbe, \& Buss, 2019; Tooby \& Cosmides, 1992). Such underlying mechanisms underlie some nonverbal expressions, such as infants across cultures smiling in response to a familiar voice or tickling (Eibl-Eibesfeldt, 1973). In addition to these prepared mechanisms, nonverbal expressions can also be learned in a manner that is culturally variable. For instance, tongue protrusion is considered a sign of a culturally-specific emotional state, lajya (roughly translated as shame) in the Indian Orissa culture (Menon \& Shweder, 1994). Evolutionarily prepared and social learning mechanisms thus together shape human behaviour.

While evolutionary theorising does not propose universal manifest behaviour, it does posit species-typical evolved psychological mechanisms (e.g., Lewis et al., 2017). These mechanisms evolved to process cues from our ancestral cultural environments, and mesh with statistical regularities in the specific contemporary environment of the organism (Brown, 1991; Tooby \&Cosmides, 1992). Evolved psychological mechanisms allow humans to learn from features that are culturally and ecologically variable by interacting with recurrent structures present in their environment. Consequently, systematic variability across cultural environments can lead to systematically variable psychological output. The operation of a psychological mechanism can be thought in three stages of information-processing in general: environmental and cultural cues are processed as input in evolved informationprocessing mechanisms, which are then operated upon by computational procedures, and subsequently turn into variable output (e.g., Al-Shawaf \& Lewis, 2017). Universality is not predicted at the level of output, but rather at the level of computational design. Variable output is a sign that the contextual proximate inputs differ across cultural environments. Evolutionary approach thus offers a comprehensive framework that links proximate mechanisms to the distal origins of those mechanisms (see Lewis et al. 2017, for a discussion on proximate and ultimate level of analysis). For instance, strong evidence has been found for prelinguistic colour categories in infants (Skelton et al., 2017), pointing to universal colour categories that are present before colour word learning. However, although infant colour perception has a universal foundation, learning language changes colour perception (Forbes \& Plunkett, 2018). Indeed, colour perception reflects not only universal tendencies, but also variation based on local linguistic convention (e.g., Reiger \& Kay, 2009; Roberson, Hanley, 
\& Pak, 2009; Roberson, Pak, \& Hanley, 2008). Language and culture thus shape how evolved psychological mechanisms are instantiated.

\section{Human emotions as variations on themes}

In understanding evolved and learned mechanisms, cultural differences can be conceptualised as variations around common themes of human universals. Depending on environmental circumstances, species-typical traits may develop differently (H. C. Barrett, 2020). For instance, people who forage daily develop more sophisticated odour categorization skills than city-dwellers, reflecting a biological potential that only develops fully when utilized (Majid \& Kruspe, 2018). Evolutionary hypotheses posit that evolved mechanisms respond adaptively to environmental conditions. For instance, cross-cultural research on mate choice has shown varying preferences. The male preference for low waistto-hip ratio and slimness is universal, but it varies with ecology in response to changes in the local cue structure (e.g., Yu \& Shepard, 1998; Swami, 2015). Similarly, the preference for average faces is universal, but the average face shape in a population is determined by faces in the local environment, resulting in variability across groups in which faces are preferred (Apicella, Little, Marlowe, 2007). Shared human traits thus develop differently in response to environmental conditions.

Like other psychological mechanisms, human emotions can be positioned within the framework of universal variations on a theme. On this view, emotions would be expected to exist across cultures, but cross-cultural differences should occur in a manner that reflects differences in ecology and culture across groups. However, there is no consensus on how to conceptualise emotions, which makes this proposal challenging to evaluate (Sauter \& Russell, 2020). Yet, most scholars of emotion agree that it is useful to distinguish between different components of emotion, including felt experience, cognitive appraisals (i.e., evaluations), nonverbal expressions, and physiological changes (Moors, 2017; Russell, 2003; Scarantino, 2016). These distinctions are particularly pertinent in discussions of cross-cultural similarities and variations, since the extent to which culture modulates different components of emotion is inconsistent across emotion components (see Manokara \& Sauter, 2020). Specifically, it has been proposed that culture strongly influences subjective emotion experiences, but weakly influences nonverbal expressions (Levenson, Soto, \& Pole, 2007). Next, we therefore turn to discussing cross-cultural similarities and variations for these two key emotion components: emotion experience and nonverbal expressions.

Emotion experience. Cultural differences in emotion experience can be thought of as variations on themes that reflect prototypical 'scripts' related to a type of emotion experience (Lazarus, 1991). Elements of such themes include elicitors (causes), appraisals, and tendencies to take different actions. Integration of these elements into a coherent script links a type of situation to the subjective emotion experience. For instance, prototypical scripts for experiencing sadness include an irrevocable loss, while fear involves facing an immediate danger. In an evolutionary psychological framework, the themes would be expected to be universal, yet may predict divergent emotional responses across cultures, which in turn would mean cross-culturally variable emotion experiences.

In the discussion of emotion in relation to culture, a commonly used concept is individualism-collectivism, which denotes the extent to which a cultural group values individual needs, wishes and goals over those of the group or collective (Hofstede, 1983, 2001). Cultures that are more individualistic (e.g., North America and Western Europe), emphasize autonomy and personal goals. In contrast, cultures that are less individualistic and more collectivistic (e.g., East Asia and South America) place more emphasis on relationships 
with others and social harmony. Much of the research on emotion and culture draws on this distinction.

In the context of emotional experience across cultures, shame is an illustrative example for the notion of cross-cultural variation on a common theme. Shame is an emotion that, across cultures, involves a negative evaluation of the self (Tangney, 1991; Tracy \& Robins, 2004). Shame arises when one's shortcomings are exposed to others, and results from a real or imagined negative evaluation by others (Wong \& Tsai, 2007). Shame fulfils several functions, including reflecting our concern for others (Lebra, 1988) and preserving our sense of personal identity (Hultberg, 1988; Scheff, 1988). It is believed that people experience shame in all societies; indeed, that it is so important for social control that it is unlikely that a society could be maintained without it (Creighton, 1988). Field experiments including small communities around the world have found that, despite widely varying languages, cultures, and subsistence modes, shame is closely related with devaluation of local audiences (Sznycer et al., 2018). Complementing this cross-cultural consistency, there are important differences in how shame manifests in different cultures, and how different groups sees shame. In fact, shame experiences can be considered as variations on a relational theme in at least three ways.

Firstly, there is a difference across cultures in how socially desirable shame is considered to be. In individualistic cultures, shame is considered highly undesirable, as it signals incompetence, inferiority or weakness (Goffman, 1967), and undermines positive self-regard (Kitayama et al., 2006). In contrast, in collectivistic cultures, shame is not perceived as particularly unpleasant (Romney, Moore, \& Rusch, 1997), possibly because it is seen as conducive to self-improvement and perspective taking (Heine et al., 1999). In collectivistic cultures, being aware of one's shortcomings and actively correcting them helps individuals realign with social norms and expectations.

Secondly, the antecedents of shame can be different across cultures (e.g., Boiger, Güngör, Karasawa \& Mesquita, 2014). For example, for Americans, situations in which their personal flaws are revealed to others, like getting sick during a team game, are seen as more shameful. For Japanese people, situations that imply a loss of public face to the protagonists themselves, like getting caught during self-talk by a stranger, are perceived as more shameful (Boiger, Mesquita, Uchida, \& Barrett, 2013). In American culture, maintaining dignity is aimed by an independent, autonomous self, while maintaining face is concerned by an interdependent, relational self in Japanese culture.

Thirdly, cross-cultural variability can illuminate the manner in which cultures differentially highlight, ignore, or group various facets of emotional experience (Fessler, 2004). Shame fails to achieve the central tasks of an independent self (Kitayama, Markus, \& Matsumoto, 1995), and consequently shame is less salient and indeed made relatively invisible in individualistic, compared to collectivistic, cultures (Scheff, 1988). In individualistic cultures, shame is unarticulated in early child development, and the development of shame instead takes place relatively late in development (Miake \& Yamazaki, 1995). Moreover, shame representations are less elaborate in individualistic cultures as compared to other cultural contexts (Mascolo, Fischer, \& Li, 2003; Shaver, Wu, \& Schwartz, 1992). Notably, the difference between shame and guilt varies across cultures. In individualistic cultures such as the United States, shame is often used synonymously with guilt, but shame arises when one's shortcomings are attributed to oneself, while guilt comes when one's focus is on a particular negative act or circumstance (Wong \& Tsai, 2007; Robertson et al., 2018). In fact, exactly because shame may be "overshadowed" by guilt in 
individualistic cultures, a fuller understanding of shame experiences can only be arrived at by studying shame across cultures (Fessler, 2004).

Shame thus illustrates the notion of emotion experience being organized as variations on a shared theme. Even though clear cross-cultural similarities exist in terms of the basic construct (Sznycer et al, 2018), the experience of shame is diverse across cultures in terms of antecedents, as well as how shame experiences relate to other related emotions. A full understanding of shame requires the study of societies varying on many dimensions, including individualism and collectivism.

Nonverbal expression. Nonverbal expression of emotion includes facial and bodily expressions like frowns, smiles, and raised fists, as well as vocalisations like laughs and screams. There is evidence for evolved mechanisms underlying the production and perception of such expressions. For instance, we more easily learn to associate certain stimuli to particular nonverbal expressions, like the acquisition of fear response to snakes (e.g., Öhman $\&$ Mineka, 2003). Associations between stimuli and expression can also be learned from ecological and environmental input that varies across cultural groups. In addition to associations to stimuli, nonverbal expressions of emotion themselves can develop differently depending on the context, leading to variations on common themes across cultures. Below, we examine how nonverbal expressions of emotions vary across cultures in terms of both perception and production.

Variation in perception and production of emotional expressions across cultures. In the domain of nonverbal expressions, cultural differences can be thought of as variations around common themes of human universals, with evolutionarily prepared capacities shaped by environmental factors like culture-specific learning. This is well illustrated by the socalled in-group advantage, which refers to the superior recognition of emotions from nonverbal expressions produced by members of one's own group. Even though reliable emotional information can be inferred across cultural groups from non-verbal cues, research has consistently shown that emotional communication is enhanced when it occurs within, as compared to between, cultural groups (Elfenbein \& Ambady, 2002; Laukka \& Elfenbein, 2020). Specifically, emotional expressions are better recognized via both facial and verbal cues when the expresser and perceiver share the same cultural background (e.g., Elfenbein, Beaupré, Lévesque, \& Hess, 2007; Laukka et al., 2016; Paulmann \& Uskul, 2014). This discrepancy in recognition accuracy reflects the fact that culturally specific factors help shape the outcomes of evolutionarily prepared mechanisms.

One explanation for the in-group advantage is that there are systematic differences between groups in terms of expressive styles. This view is articulated in dialect theory, which uses a linguistic metaphor to describe emotion as a universal language with different dialects (Elfenbein, 2003; Elfenbein et al., 2007). An American English speaker can communicate with a British English speaker reasonably well, but not quite as easily as with another American English speaker. Just like linguistic dialects, differences in expressive styles are shaped by culture-specific learning. Individuals learn the expressive behaviours that are prevalent in the environment that they grow up in. As a result, members of the same group share the same "emotion dialect" and are therefore better able to recognize each other's expressions.

There is empirical support for this account from studies that have directly examined nonverbal expressions in different cultures. For example, Elfenbein and colleagues (2007) asked participants from Canada and Gabon to pose a range of emotions using facial 
expressions. These expressions were then analysed using the Facial Action Coding System (FACS, Ekman \& Friesen, 1978), which objectively codes facial muscle movements. These muscle movements (or combination of muscle movements) are called Action Units (AUs). When examining the AUs associated with 10 different emotions, there was great convergence between the two cultures. For example, for the emotion surprise, $50 \%$ of the Canadian and $60 \%$ of the Gabonese encoders showed the prototypical expression (AU1+AU2 +AU5 with mouth open). At the same time, reliable cultural differences were observed, demonstrating culture-specific variations around the universal facial expressions. For example, when expressing sadness, while individuals from both cultures showed the prototypical expression involving AU1 (27\% and 13\%) and AU4 (67\% and 33\%), $43 \%$ of Gabonese encoders showed AU 56 (head tilt), while none of the Canadian encoders did. Interestingly, there were greater cross-cultural differences for expressions of emotions that are typically elicited in social interactions (e.g., anger and shame), than those that are often elicited by non-social events (e.g., fear and disgust).

A recent study of expressive behaviours associated with 22 different emotions across five different cultures found further evidence for culture-specific variations around universal themes (Cordaro et al., 2018). The researchers identified what they called International Core Patterns (ICPs), denoting patterns of expressive behaviours that were conserved across cultures. On average, about half of any participant's expressions of any emotion involved movements from the ICPs. At the same time, unique cultural accents were observed that differed across cultures. Similar patterns were observed for posed and spontaneous expressions of emotions. These findings point to culture-specific expressions around universally shared core expression patterns; these differences in the production of expressions likely contribute to the challenges occurring when interpreting expressions by members of other groups.

Culture-specific learning can thus shape some aspects of the ways in which emotions are expressed. In addition, cultural learning is an important determinant of cultural identity. It has been suggested that the extent to which a perceiver identifies with an expresser determines their motivation to decode signals from the expresser (Thibault, Bourgeois \& Hess, 2006). According to this view, the more the perceiver judges the expresser to be a member of their own group, the more motivated the perceiver will be to attempt to interpret the emotional expression. This in turn can lead to higher decoding accuracy. The motivational view thus provides a complementary explanatory framework in which the ingroup advantage arises from cultural identity, which is also an outcome of environmental factors.

The motivational view aligns with evolutionary accounts that highlight that investing more resources in members of one's own group contributes to maximizing inclusive fitness (Hamilton, 1964, Abbot et al., 2011). There is empirical support for this view. Superior processing strategies are used when processing in-group, as compared to out-group, expressions. For example, when judging in-group faces, perceivers engage in more configural processing (i.e., processing the interdependence and spatial relationship between face parts) as opposed to analytical processing (i.e., processing the different facial components separately; Hugenberg \& Corneille, 2009). Configural processing has been shown to be beneficial for the decoding of emotional facial expressions (Calder et al., 2000). However, the enhanced decoding of emotional expressions from in-group members only occurs during longer presentation times, suggesting that the higher recognition accuracy for in-group signals requires additional processing time (Young \& Hugenberg, 2010). 
Nonverbal expression can also vary across cultures due to differences in display rules, that is, norms about how appropriate it is to display emotional expressions in a particular context (Friesen, 1972; Matsumoto, 1990; Manokara et al., 2020). Though there are norms regarding the expression of emotion in certain situations in every culture, considerable variations exist in these social rules across cultural groups. Specifically, display rules vary along with important cultural dimensions, including individualism-collectivism (Hofstede, 1983; 2001).

People from more collectivistic cultures have been shown to be less expressive overall (Matsumoto et al., 2008). While there is no evidence that individuals in collectivistic cultures experience fewer or less intense emotions, they are under more social pressure to regulate their emotion displays. This may reflect the fact that a typical goal of individuals in individualistic cultures is to be independent of others, and attending to and expressing one's own attributes such as personal feelings can help distinguish oneself from others (Markus \& Kitayama, 1991; Suh, Diener, Oishi \& Triandis, 1991). In contrast, collectivistic cultures prioritise self-control and accommodating the needs of others over personal desires (TamisLeMonda et al., 2008; Triandis, 1995), which might result in less expression of personal feelings. Cultural differences in the degree of individualism-collectivism have been found to map onto the strength of norms for expressing emotions (Matsumoto et al., 2008).

Display rules again illustrate how nonverbal expression can be thought of as variations on a common theme across cultures: Evolutionarily prepared nonverbal expressions are shaped by culturally learned display rules. While all cultures have norms dictating how and when one should express their emotions, display rules differ systematically across cultures. These rules are influenced by broader norms and values within a culture, for example those that correspond to individualism-collectivism. These patterns of behaviour are self-enforcing within a group and are acquired through culture-specific learning. From an evolutionary perspective, conforming to group norms serves an important signalling function and can confer prestige and better evaluations of fitness by in-group members (Cheng et al., 2013; Henrich \&Gil-White, 2001; Wenegrat et al., 1996)

\section{How to conceptualise common themes underlying emotions?}

Approaching emotion components as variations around universal themes raises the question of how best to characterise those themes. Next, we outline three accounts of emotions with different implications for how to understand the cross-culturally shared themes underlying emotions. We sketch three views on emotion in terms of what each theory considers to be evolutionarily prepared and what is thought to be culturally learned: The basic emotion theory, appraisal theory, and psychological constructionism. We do not advocate for one account over the others, but outline their views on how best to conceptualise emotions.

Affect programs: The Basic Emotion Theory. According to basic emotion theory, emotions are distinct, brief states that were selected for over evolutionary time for their adaptive value in dealing with important ancestral situations (e.g., Ekman, 1992). Basic emotions thus aided organisms in dealing with recurring challenges and opportunities over the course of evolution (e.g., Tooby \& Cosmides, 2008). Examples include fear for natural predators, disgust for rotten or toxic food, and joy for playful interactions. All humans are posited to have a biologically innate, latent affect program for each basic emotion. What these emotions are varies across theorists, but frequently cited basic emotions are anger, fear, disgust, sadness, surprise, and joy (but see Keltner \& Cordaro, 2017 for a more extensive list). The basic emotion framework thus postulates a specialised affect program for each emotion, which can be conceptualised as superordinate programs for coordinating 
functionally specialized mechanisms, including physiological changes and behaviour (e.g., Al-Shawaf, Conroy-Beam, Asao, \& Buss, 2016; Al-Shawaf \& Lewis, 2017; Tooby \& Cosmides, 2008). These superordinate programs direct the processing of environmental or somatic cues to aid the organism's reaction to a recurring type of adaptive problem.

Affect programs can be triggered by distinct universal antecedents, like being chased by a predator and smelling rotten food. In addition to universal antecedents, learned elicitors can also trigger affect programs. Regardless of the trigger, affect programs activate the same cascade of emotion components, including physiological, expressive, and subjective responses. On this view, emotions are thus domain-specific modules that facilitate adaptive reactions to particular kinds of ancestral situations. However, emotions can still be shaped by cultural learning, including higher-order cognition (Izard, 2007). The basic emotion theory thus posits evolved mechanisms for discrete emotions, and modulation of emotion processes by cultural learning.

Appraisals: Appraisal theory. The appraisal approach argues that emotional experiences are triggered by immediate and intuitive evaluations (appraisals) of our environment (e.g., Ellsworth, 2013). Commonly proposed appraisal dimensions are novelty, valence, goal relevance, certainty, and agency. Appraisal theorists do not focus on specific types of situations (e.g., the presence of a snake), but rather on a small set of appraisal dimensions. These dimensions specify constituent elements of emotional experience. While some theorists argue that appraisals trigger a system similar to affect programs posited in basic emotion approach (Ekman, 1992; Keltner, Horberg, \& Oveis, 2006; Roseman, 1991), others propose that different appraisal dimensions influence emotion components separately (Scherer, 2001; Moors, 2014). In this second view, specific changes in emotion episodes (e.g., facial muscle movements, vocal changes) are explained by specific combinations of appraisal dimensions triggered by the event, not by a categorical emotion mechanism.

According to the appraisal approach, appraisals are evolutionarily prepared and constitute the core of emotion. Some appraisal theorists (e.g., Scherer \& Moors, 2019) suggest that certain patterns of individual appraisal dimensions were more common throughout human evolutionary history. Those patterns would have resulted an increased temporal synchronisation and coherence among several appraisal dimensions. The appraisal framework thus proposes preparedness for appraisals, which result in emotion episodes when the components of episodes are sufficiently synchronised. However, depending on the culture, people might evaluate emotion-eliciting situations differently, resulting in culturally variable emotional experiences and expressions (Ellsworth, 2013; Scherer, 1997).

General-purpose mechanisms: Psychological constructivism. In the psychological constructionist framework, emotions are shaped by proximal socio-contextual factors and not by specialised evolved adaptations (Russell, 2009). From this perspective, emotions are produced by general-purpose mechanisms (L. F. Barrett, 2014). A central feature is core affect, which refers to bodily sensations along the dimensions of arousal (energised or enervated) and valence (good or bad). Core affect is, however, not specific to emotions; bodily sensations are always in some state of arousal and valence. A range of additional processes, such as sensory-perceptual-cognitive processing, respondent behaviours, and instrumental actions, are included in the suite of general-purpose mechanisms thought to underlie emotions according to psychological constructionism.

According to psychological constructionism, the general-purpose mechanisms (but not specific emotion categories or appraisal dimensions) are prepared and consequently universal. In contrast, subjective experience is thought to reflect culturally specific learning processes (Mesquita, Barrett, \& Smitt, 2010). Psychological constructivism thus posits 
cultural variability in emotions, but universality of domain-general mechanisms including core affect.

\section{Conclusions}

Can evolutionary psychology inform our understanding of cross-cultural consistency and variability in human emotion? We discussed this question in the context of the notion that evolved psychological mechanisms lead to human universals that are instantiated as variations around cross-culturally shared themes (H. C. Barrett, 2020). According to this idea, specific traits develop differently depending on environmental circumstances, leading to variations on that trait. We propose that human emotions can be placed in the framework of cultural differences as variations on a universal theme. For instance, evidence for crosscultural differences in the experience of shame and emotion recognition from nonverbal expressions reflect variability on universally shared themes. These examples highlight how evolutionarily prepared mechanisms produce outcomes that are shaped by environmental factors like cultural learning. Although there is no consensus on how to best conceptualise the themes, we outlined the perspectives of three major emotion theories to illustrate some alternative views on this issue.

From an evolutionary psychological perspective, cross-cultural variation in emotion should reflect key differences in ecology and cultural context. However, cross-cultural research on emotion has primarily ended to focus on testing the degree of consistency or variability, while less attention has been given to the factors driving the variability.

Nevertheless, recent research points to aspects of cultural variation in emotionally expressive behaviour being shaped by historical heterogeneity, that is the extent to which the present-day population in a country descended from many versus few source countries (Rychlowska et al., 2015). This approach of establishing potential driving forces of cross-cultural differences from ecology and culture has the potential to open up a rich avenue for cross-cultural research. To explain findings regarding cultural variation in human emotion, future research might also more explicitly contrast predictions based the three emotion theories we outlined, in terms of how htye explain cross-cultural variability. All in all, the idea of cultural differences as variations on a theme around universals provides an opportunity for testing evolutionary hypotheses regarding cross-cultural variation in human emotion. 


\section{References}

Abbot, P., Abe, J., Alcock, J., Alizon, S., Alpedrinha, J. A., Andersson, M., ... \& Barton, N. (2011). Inclusive fitness theory and eusociality. Nature, 471, E1-E4. https://doi.org/10.1038/nature09835

Al-Shawaf, L., Conroy-Beam, D., Asao, K., \& Buss, D. M. (2016). Human emotions: An evolutionary psychological perspective. Emotion Review, 8, 173-186. https://doi.org/10.1177/1754073914565518

Al-Shawaf, L., \& Lewis, D. M. (2017). Evolutionary psychology and the emotions. In V. Zeigler-Hill \& T. K. Shackelford (Eds.), Encyclopedia of personality and individual differences (pp. 1-10). Basel, Switzerland: Springer. https://doi.org/10.1007/978-3319-28099-8_516-1

Al-Shawaf, L., Lewis, D. M., Barbaro, N., \& Wehbe, Y. S. (2020). The products of evolution: conceptual distinctions, evidentiary criteria, and empirical examples. In T. K. Shackelford (Ed.) The SAGE handbook of evolutionary psychology (pp. 70-95). Thousand Oaks, CA: Sage.

Al-Shawaf, L., Lewis, D. M. G., Wehbe, Y., \& Buss, D. M. (2019). Context, environment, and learning in evolutionary psychology. In T. K. Shackelford, \& V. A. WeekesShackelford (Eds.). Encyclopedia of evolutionary psychological science (pp. 1-12). New York, NY: Springer.

Anderson, M.L., \& Finlay, B.L. (2014). Allocating structure to function: the strong links between neuroplasticity and natural selection. Frontiers in Human Neuroscience, 7, 918. https://doi.org/10.3389/fnhum.2013.00918

Apicella, C. L., Little, A. C., \& Marlowe, F. W. (2007). Facial averageness and attractiveness in an isolated population of hunter-gatherers. Perception, 36, 1813-1820. https://doi.org/10.1068/p5601

Baldwin, J. R., Faulkner, S. L., Hecht, M. L., \& Lindsley, S. L. (Eds.). (2006). Redefining culture: Perspectives across the disciplines. Lawrence Erlbaum Associates Publishers. https://doi.org/10.4324/9781410617002

Barrett, H. C. (2014). The shape of thought. Oxford, UK: Oxford University Press.

Barrett, H. C., \& Kurzban, R. (2006). Modularity in cognition: framing the debate. Psychological Review, 113, 628. https://doi.org/10.1037/0033295X.113.3.628

Barrett, L. F. (2011). Was Darwin wrong about emotional expressions?. Current Directions in Psychological Science, 20, 400-406. https://doi.org/10.1177/0963721411429125

Barrett, L. F. (2014). The conceptual act theory: A précis. Emotion Review, 6, 292-297. https://doi.org/10.1177/1754073914534479

Boiger, M., Güngör, D., Karasawa, M., \& Mesquita, B. (2014). Defending honour, keeping face: Interpersonal affordances of anger and shame in Turkey and Japan. Cognition and Emotion, 28, 1255-1269. https://doi.org/10.1080/02699931.2014.881324

Boiger, M., Mesquita, B., Uchida, Y., \& Barrett, L. F. (2013). Condoned or Condemned: The Situational Affordance of Anger and Shame in the United States and Japan.

Personality and Social Psychology Bulletin, 39, 540-553. https://doi.org/10.1177/0146167213478201 
Brown, D. E. (1991). Human universals. Philadelphia, PA: Temple University Press.

Bryant, G. A. (2020). Evolution, structure, and functions of human laughter. In Floyd, K., Weber, R. (Eds.), Handbook of communication science and biology (pp. 63-77). New York, NY: Routledge. https://doi.org/10.4324/9781351235587-7

Bryant, G. A., Fessler, D. M., Fusaroli, R., Clint, E., Aarøe, L., Apicella, C. L., ... \& De Smet, D. (2016). Detecting affiliation in colaughter across 24 societies. Proceedings of the National Academy of Sciences, 113, 4682-4687. https://doi.org/10.1073/pnas.1524993113

Calder, A. J., Young, A. W., Keane, J., \& Dean, M. (2000). Configural information in facial expression perception. Journal of Experimental Psychology: Human perception and performance, 26, 527- 551. https://doi.org/10.1037/0096-1523.26.2.527

Cheng, J. T., Tracy, J. L., Foulsham, T., Kingstone, A., \& Henrich, J. (2013). Two ways to the top: Evidence that dominance and prestige are distinct yet viable avenues to social rank and influence. Journal of Personality and Social Psychology, 104(1), 103125. https://doi.org/10.1037/a0030398

Cordaro, D. T., Keltner, D., Tshering, S., Wangchuk, D., \& Flynn, L. M. (2016). The voice conveys emotion in ten globalized cultures and one remote village in Bhutan. Emotion, 16, 117-128. https://doi.org/10.1177/0956797618778235

Cordaro, D. T., Sun, R., Keltner, D., Kamble, S., Huddar, N., \& McNeil, G. (2018). Universals and cultural variations in 22 emotional expressions across five cultures. Emotion, 18, 75. https://doi.org/10.1037/emo0000302

Cosmides, L., \& Tooby, J. (1994). Origins of domain specificity: The evolution of functional organization. In L. Hirschfeld \& S. Gelman (Eds.), Mapping the mind: Domain specificity in cognition and culture (pp. 85-116). New York, NY: Cambridge University Press. https://doi.org/10.1017/CBO9780511752902.005

Cosmides, L., \& Tooby, J. (2000). Evolutionary psychology and the emotions. In M. Lewis \& J. M. Haviland-Jones (Eds.), Handbook of emotions (2nd ed., pp. 91-115). New York, NY: Guilford.

Creighton, M. (1990). Revisiting Shame and Guilt Cultures: A Forty-Year Pilgrimage. Ethos, 18(3), 279-307. Retrieved November 24, 2020, from http://www.jstor.org/stable/640338

Crivelli, C., Russell, J. A., Jarillo, S., \& Fernández-Dols, J. M. (2017). Recognizing spontaneous facial expressions of emotion in a small-scale society of Papua New Guinea. Emotion, 17, 337. https://doi.org/10.1037/emo0000236

Diefendorff, J., Morehart, J., \& Gabriel, A. (2010). The influence of power and solidarity on emotional display rules at work. Motivation and Emotion, 34, 120-132. https://doi.org/10.1007/s11031-010-9167-8

Douglas, W. Y., \& Shepard, G. H. (1998). Is beauty in the eye of the beholder?. Nature, 396, 321-322. https://doi.org/10.1038/24512

Eibl-Eibesfeldt, I. (1973). Expressive behaviour of the deaf and blind born. In M. von Cranach \& I. Vine (Eds.), Social communication and movement (pp. 163-194). New York, NY: Academic Press.

Ekman, P. (1992). An argument for basic emotions. Cognition and Emotion, 6, 169-200. https://doi.org/10.1080/02699939208411068 
Ekman, P., \& Cordaro, D. (2011). What is meant by calling emotions basic. Emotion Review, 3, 364-370. https://doi.org/10.1177/1754073911410740

Ekman, P., \& Friesen, W. V. (1978). Facial Action Coding System: Investigator's Guide. Consulting Psychologists, Palo Alto, CA. https://doi.org/10.1037/t27734-000

Elfenbein, H. A. (2013). Nonverbal dialects and accents in facial expressions of emotion. Emotion Review, 5, 90-96. https://doi.org/10.1177/1754073912451332

Elfenbein, H. A., \& Ambady, N. (2002). On the universality and cultural specificity of emotion recognition: a meta-analysis. Psychological Bulletin, 128, 203. https://doi.org/10.1037/0033-2909.128.2.203

Elfenbein, H. A., Beaupré, M., Lévesque, M., \& Hess, U. (2007). Toward a dialect theory: Cultural differences in the expression and recognition of posed facial expressions. Emotion, 7, 131-146. https://doi.org/10.1037/1528-3542.7.1.131

Ellsworth, P. C. (2013). Appraisal theory: Old and new questions. Emotion Review, 5, 125 131. https://doi.org/10.1177/1754073912463617

Fessler, D. (2004). Shame in two cultures: Implications for evolutionary approaches. Journal of Cognition and Culture, 4, 207-262. https://doi.org/10.1163/1568537041725097

Forbes, S. H., \& Plunkett, K. (2020). Linguistic and cultural variation in early color word learning. Child Development, 91, 28-42. https://doi.org/10.1111/cdev.13164

Friesen, W. V. (1972). Cultural differences in facial expressions in a social situation: An ex pelimental test of the concept of display rules. Unpublished doctoral dissertation, University of California, San Francisco.

Gangestad, S. W., Haselton, M. G., \& Buss, D. M. (2006). Evolutionary foundations of cultural variation: Evoked culture and mate preferences. Psychological Inquiry, 17, 75-95. https://doi.org/10.1207/s15327965pli1702 1

Gibson, D. E., \& Schroeder, S. J. (2002). Grinning, frowning, and emotionless: Agent perceptions of power and their effects on felt and displayed emotions in influence attempts. In N. M. Ashkanasy, W. J. Zerbe, \& C. E. J. Hartel (Eds.), Managing emotions in the workplace (pp. 184-211). New York: M. E. Sharpe.

Goffman, E. (1967). Interaction ritual: essays on face-to-face interaction. Aldine.

HA, F. I. (1995). Shame in Asian and Western Cultures. American Behavioral Scientist, 38, 1114-1131. https://doi.org/10.1177/0002764295038008007

Hamilton, W. D. (1964). The genetical evolution of social behaviour. II. Journal of Theoretical Biology, 7, 17-52. https://doi.org/10.1016/0022-5193(64)90039-6

Heine, S. J., Lehman, D. R., Markus, H. R., \& Kitayama, S. (1999). Is there a universal need for positive self-regard? Psychological Review, 106, 766-794. https://doi.org/10.1037/0033-295X.106.4.766

Henrich, J., \& Gil-White, F. J. (2001). The evolution of prestige: Freely conferred deference as a mechanism for enhancing the benefits of cultural transmission. Evolution and Human Behavior, 22, 165-196. https://doi.org/10.1016/S1090-5138(00)00071-4

Heyes, C. (2020). Psychological Mechanisms Forged by Cultural Evolution. Current Directions in Psychological Science, 29, 399-404. https://doi.org/10.1177/0963721420917736 
Hofstede, G. (2001). Culture's consequences: Comparing values, behaviors, institutions and organizations across nations. Sage publications.

Hofstede, G. (1983). Dimensions of national cultures in fifty countries and three regions. In J. Deregowski, S. Dziurawiec, \& R. Annis (Eds.), Explications in cross-cultural psychology. Lisse: Swets \& Zeitlinger.

Hugenberg, K., \& Corneille, O. (2009). Holistic processing is tuned for ingroup faces. Cognitive Science, 33, 1173-1181. https://doi.org/10.1111/j.1551-6709.2009.01048.x

Hultberg, P., \& Hultberg, P. (1988). Shame--a hidden emotion. Journal of Analytical Psychology, 33, 109-126. https://doi.org/10.1111/j.1465-5922.1988.00109.x

Izard, C. E. (2007). Basic emotions, natural kinds, emotion schemas, and a new paradigm. Perspectives on Psychological Science, 2, 260-280. https://doi.org/10.1111/j.17456916.2007.00044.x

Jack, R. E., Garrod, O. G., Yu, H., Caldara, R., \& Schyns, P. G. (2012). Facial expressions of emotion are not culturally universal. Proceedings of the National Academy of Sciences, 109, 7241-7244. https://doi.org/10.1073/pnas.1200155109

Keltner, D., \& Cordaro, D. T. (2017). Understanding Multimodal Emotional Expressions: Recent Advances in Basic Emotion Theory. In J.-M. Fernandez-Dols \& J. A. Russell (Eds.), The Science of Facial Expression (pp. 57-76). New York: Oxford University Press. https://doi.org/10.1093/acprof:oso/9780190613501.003.0004

Keltner, D., Horberg, E. J., \& Oveis, C. (2006). Emotions as moral intuitions. Affect in Social Thinking and Behavior, 161-175.

Kitayama, S., Markus, H. R., \& Matsumoto, H. (1995). Culture, self, and emotion: A cultural perspective on "self-conscious" emotions. In J. P. Tangney\& K. W. Fischer (Eds.), Self-conscious emotions: The psychology of shame, guilt, embarrassment, and pride (pp. 439-464). New York: Guilford Press.

Kitayama, S., Mesquita, B., \& Karasawa, M. (2006). Cultural affordances and emotional experience: Socially engaging and disengaging emotions in Japan and the United States. Journal of Personality and Social Psychology, 91, 890-903. https://doi.org/10.1037/0022-3514.91.5.890

Kline, M. A., Shamsudheen, R., \& Broesch, T. (2018). Variation is the universal: making cultural evolution work in developmental psychology. Philosophical Transactions of the Royal Society B: Biological Sciences, 373, 20170059. https://doi.org/10.1098/rstb.2017.0059

Laukka, P., \& Elfenbein, H. A. (2020). Cross-Cultural Emotion Recognition and In-Group Advantage in Vocal Expression: A Meta-Analysis. Emotion Review, 1754073919897295. https://doi.org/10.1177/1754073919897295

Laukka, P., Elfenbein, H. A., Söder, N., Nordström, H., Althoff, J., Iraki, F. K. E., ... \& Thingujam, N. S. (2013). Cross-cultural decoding of positive and negative nonlinguistic emotion vocalizations. Frontiers in Psychology, 4, 353. https://doi.org/10.3389/fpsyg.2013.00353

Laukka, P., Elfenbein, H. A., Thingujam, N. S., Rockstuhl, T., Iraki, F. K., Chui, W., \& Althoff, J. (2016). The expression and recognition of emotions in the voice across five nations: A lens model analysis based on acoustic features. Journal of Personality and Social Psychology, 111, 686-705. https://doi.org/10.1037/pspi0000066 
Lazarus, R. S. (1991). Emotion and adaptation. New York, NY: Oxford University Press.

Lebra, T. S. (1973). Compensative justice and moral investment among Japanese, Chinese, and Koreans. The Journal of Nervous and Mental Disease, 157, 278-291.

Levenson, R. W., Soto, J., \& Pole, N. (2007). Emotion, biology, and culture. In S. Kitayama \& D. Cohen (Eds.), Handbook of cultural psychology. New York, NY: Guilford Press.

Lewis, D. M., Al-Shawaf, L., Conroy-Beam, D., Asao, K., \& Buss, D. M. (2017). Evolutionary psychology: A how-to guide. American Psychologist, 72, 353. https://doi.org/10.1037/a0040409

Liddell, B. J., \& Williams, E. N. (2019). Cultural differences in interpersonal emotion regulation. Frontiers in Psychology, 10, 999. https://doi.org/10.3389/fpsyg.2019.00999

Majid, A., \& Kruspe, N. (2018). Hunter-gatherer olfaction is special. Current Biology, 28, 409-413. https://doi.org/10.1016/j.cub.2017.12.014

Manokara, K., Fischer, A., Diwan, K., Cao, C., Fang, X., \& Sauter, D. (2020). When to Hide your (Tears of) Joy: Display Rules for Positive Emotions. https://doi.org/10.31219/osf.io/4uaym

Manokara K. \& Sauter, D. A. (2020). The foundation from which cultural variability of emotion emerges. In J. De Leersnyder (Ed.) Culture and Emotion. Cambridge University Press. Under review.

Markus, H., \& Kitayama, S. (1991). Culture and the self: Implications for cognition, emotion, and motivation. Psychological Review, 98, 224-253.

Mascolo, M. F., \& Fischer, K. W. (1995). Developmental transformations in appraisals for pride, shame, and guilt. In J. P. Tangney \& K. W. Fischer (Eds.), Self-conscious emotions: The psychology of shame, guilt, embarrassment, and pride (pp. 64-113). Guilford Press.

Mascolo, M. J., Fischer, K. W., \& Li, J. (2003). Dynamic development of component systems of emotions: Pride, shame, and guilt in China and the United States. In R. J.

Davidson, K. Scherer, \& H. H. Goldsmith (Eds.), Handbook of affective science (pp. 375-408). Oxford, England: Oxford University Press.

Matsumoto, D. (1990). Cultural similarities and differences in display rules. Motivation and Emotion, 14, 195-214. https://doi.org/10.1007/BF00995569

Matsumoto, D., Yoo, S. H., \& Fontaine, J. (2008). Mapping expressive differences around the world: The relationship between emotional display rules and individualism versus collectivism. Journal of Cross-Cultural Psychology, 39(1), 55-74.

Mesquita, B., Barrett, L. F., \& Smith, E. R. (Eds.). (2010). The mind in context. New York, NY: Guilford Press.

Menon, U. \& Shweder, R.A. (1994). Kali's Tongue: Cultural psychology and the power of 'shame' in Orissa, India. In Shinobu Kitayama \& Hazel Markus (Eds), Emotion and culture: Empirical studies of mutual influence (pp. 241-284), Washington DC: APA Books.

Miake, K., \& Yamazaki, K. (1995). Self-conscious emotions, child rearing, and psychopathology in Japanese culture. In J. P. Tangney \& K. W. Fischer (Eds.), Selfconscious emotions (pp. 488-504). New York: Guilford. 
Moors, A. (2014). Flavors of Appraisal Theories of Emotion. Emotion Review, 6, 303-307. https://doi.org/10.1177/1754073914534477

Öhman, A., \& Mineka, S. (2003). The malicious serpent: Snakes as a prototypical stimulus for an evolved module of fear. Current Directions in Psychological Science, 12, 5-9. https://doi.org/10.1111/1467-8721.01211

Paulmann, S., \& Uskul, A. K. (2014). Cross-cultural emotional prosody recognition: Evidence from Chinese and British listeners. Cognition and Emotion, 28, 230-244. https://doi.org/0.1080/02699931.2013.812033

Pauw, L. S., Vu, T., Sun, R., Vuillier, L., Milek, A., \& Sauter, D. (2020, October 19). Emotion Regulation and Wellbeing: A Cross-Cultural Study During the COVID-19 Outbreak. https://doi.org/10.31234/osf.io/9qrw5

Regier, T., \& Kay, P. (2009). Language, thought, and color: Whorf was half right. Trends in Cognitive Sciences, 13, 439-446. https://doi.org/10.1016/j.tics.2009.07.001

Richerson PJ, Boyd R. 2005 Not by genes alone: how culture transformed human evolution. Chicago, IL: University of Chicago Press. https://doi.org/10.7208/chicago/9780226712130.001.0001

Roberson, D., Hanley, J. R., \& Pak, H. (2009). Thresholds for color discrimination in English and Korean speakers. Cognition, 112, 482-487. https://doi.org/10.1016/j.cognition.2009.06.008

Roberson, D., Pak, H., \& Hanley, J. R. (2008). Categorical perception of colour in the left and right visual field is verbally mediated: Evidence from Korean. Cognition, 107, 752-762. https://doi.org/10.1016/j.cognition.2007.09.001

Robertson, T. E., Sznycer, D., Delton, A. W., Tooby, J., \& Cosmides, L. (2018). The true trigger of shame: Social devaluation is sufficient, wrongdoing is unnecessary.

Evolution and Human Behavior, 39, 566-573. https://doi.org/10.1016/j.evolhumbehav.2018.05.010

Romney, A. K., Moore, C. C., \& Rusch, C. D. (1997). Cultural universals: Measuring the semantic structure of emotion terms in English and Japanese. Proceedings of the National Academy of Sciences, 94, 5489-5494. https://doi.org/10.1073/pnas.94.10.5489

Roseman, I. J. (1991). Appraisal Determinants of Discrete Emotions. Cognition and Emotion, 5, 161-200. https://doi.org/10.1080/02699939108411034

Russell, J. A. (2009). Emotion, core affect, and psychological construction. Cognition and Emotion, 23, 1259-1283. https://doi.org/10.1080/02699930902809375

Rychlowska, M., Miyamoto, Y., Matsumoto, D., Hess, U., Gilboa-Schechtman, E., Kamble, S., . . Niedenthal, P. M. (2015). Heterogeneity of long-history migration explains cultural differences in reports of emotional expressivity and the functions of smiles. Proceedings of the National Academy of Sciences, USA, 112, E2429-E2436. https://doi.org/10.1073/pnas.1413661112

Sauter, D. A., \& Russell, J. A. (Accepted/In press). What do nonverbal expressions tell us about emotion? In A. Scarantino (Ed.), Handbook of emotion theory. Taylor \& Francis.

Scheff, T. J. (1988). Shame and conformity: The deference-emotion system. American Sociological Review, 53, 395-406. https://doi.org/10.2307/2095647 
Scherer, K. R. (1997). The role of culture in emotion-antecedent appraisal. Journal of Personality and Social Psychology, 73(5), 902.

Scherer, K. R. (2001). Appraisal Considered as a Process of Multilevel Sequential Checking. Appraisal Processes in Emotion: Theory, Methods, Research. New York: Oxford University Press.

Scherer, K. R., \& Moors, A. (2019). The emotion process: Event appraisal and component differentiation. Annual Review of Psychology, 70, 719-745. https://doi.org/10.1146/annurev-psych-122216-011854

Shaver, P. R., Wu, S., \& Schwartz, J. C. (1992). Cross-cultural similarities and differences in emotion and its representation. In M. S. Clark (Ed,), Emotion: Review of personality and social psychology (pp. 175-213). Newbury Park, CA: Sage.

Skelton, A. E., Catchpole, G., Abbott, J. T., Bosten, J. M., \& Franklin, A. (2017). Biological origins of color categorization. Proceedings of the National Academy of Sciences of the United States of America, 114, 5545-5550. https://doi.org/10.1073/pnas.1612881114

Stephen, I.D. (2014). Putting the theory before the data: Is "massive modularity" a necessary foundation of evolutionary psychology? Frontiers in Psychology, 5, 1158. https://doi.org/10.3389/fpsyg.2014.01158

Sun, R., Balabanova, A., Bajada, C. J., Liu, Y., Kriuchok, M., Voolma, S., ... Sauter, D. (2020, June 2). Psychological wellbeing during the global COVID-19 outbreak. https://doi.org/10.31234/osf.io/r7xaz

Swami, V. (2015). Cultural Influences on Body Size Ideals. European Psychologist, 20, 4451. https://doi.org/10.1027/1016-9040/a000150

Sznycer, D., Xygalatas, D., Agey, E., Alami, S., An, X. F., Ananyeva, K. I., ... \& Tooby, J. (2018). Cross-cultural invariances in the architecture of shame. Proceedings of the National Academy of Sciences, 115, 9702-9707. https://doi.org/10.1073/pnas.1805016115

Tamis-LeMonda, C., Way, N., Hughes, D., Yoshikawa, H., Kalman, R. K., \& Niwa, E. Y. (2008). Parents' goals for children: The dynamic coexistence of individualism and collectivism in cultures and individuals. Social Development, 17(1), 183-209.

Tangney, J. P. (1995). Recent advances in the empirical study of shame and guilt. American Behavioral Scientist, 38, 1132-1145. https://doi.org/10.1177/0002764295038008008

Tooby, J., \& Cosmides, L. (1990). On the universality of human nature and the uniqueness of the individual: The role of genetics and adaptation. Journal of Personality, 58, 17-67. https://doi.org/10.1111/j.1467-6494.1990.tb00907.x

Tooby, J., \& Cosmides, L. (1992). Psychological foundations of culture. In J. Barkow, L. Cosmides, \& J. Tooby (Eds.), The adapted mind: Evolutionary psychology and the generation of culture (pp. 19-136). New York, NY: Oxford University Press.

Tooby, J., \& Cosmides, L. (2008). The Evolutionary Psychology of the Emotions and Their Relationship to Internal Regulatory Variables. In M. Lewis, J.M. Haviland-Jones, L.F. Barrett (Eds.), Handbook of emotions (pp. 114-137). New York, NY: Guilford Press.

Tracy, J. L., \& Matsumoto, D. (2008). The spontaneous expression of pride and shame: Evidence for biologically innate nonverbal displays. Proceedings of the National Academy of Sciences, 105, 11655-11660. https://doi.org/10.1073/pnas.0802686105 
Tracy, J. L., \& Robins, R. W. (2006). Appraisal antecedents of shame and guilt: Support for a theoretical model. Personality and Social Psychology Bulletin, 32, 1339-1351. https://doi.org/10.1177/0146167206290212

Triandis, H. C. (1995). Individualism \& collectivism. Boulder, CO: Westview Press.

Wenegrat, B., Abrams, L., Castillo-Yee, E., \& Romine, I. J. (1996). Social norm compliance as a signaling system. I. Studies of fitness-related attributions consequent on everyday norm violations. Ethology and Sociobiology, 17, 403-416. https://doi.org/10.1016/S0162-3095(97)82225-X

Wong, Y., \& Tsai, J. (2007). Cultural models of shame and guilt. The self-conscious emotions: Theory and research, 209, 223.Wood, A., Rychlowska, M., \& Niedenthal, P. M. (2016). Heterogeneity of long-history migration predicts emotion recognition accuracy. Emotion, 16, 413. https://doi.org/10.1037/emo0000137

Young, S. G., \& Hugenberg, K. (2010). Mere social categorization modulates identification of facial expressions of emotion. Journal of Personality and Social Psychology, 99, 964. https://doi.org/10.1037/a0020400

Zerilli, J. (2017). Against the "system" module. Philosophical Psychology, 30, 231-246. https://doi.org/10.1080/09515089.2017.1280145 